\title{
Willingness-to-pay and the equivalence approach *
}

\author{
Marc Fleurbaey, Université Paris-Descartes ${ }^{\dagger}$
}

\begin{abstract}
:
This paper describes the evaluation of individual situations in terms of equivalent incomes computed from ordinary income by adding or subtracting various terms of willingness-topay. It discusses the origin of the approach and its connection with social choice theory and philosophical principles. It also examines the challenges to be addressed for empirical applications of the approach.
\end{abstract}

JEL Classification: D63, D71

Keywords: equivalent income, money-metric utility, index, social welfare

\section{OPHI Working Paper 25}

August, 2008

\footnotetext{
* Version: 15 May. This paper was presented at the OPHI Workshop on Weighting Dimensions (Oxford, 2627 May 2008).

† Université Paris-Descartes, CERSES, LSE and IDEP. Email: marc.fleurbaey@univ-paris5.fr 


\section{Introduction}

Well-being is multidimensional: income, wealth, access to public goods, health and longevity, family and social connections, social status, education and knowledge, security... The elaboration of social policy requires comparing individual situations in order to evaluate the effects of policy and to target the groups who deserve priority. The equivalence approach is one particular method, among others, that makes it possible to compare individual situations and evaluate social distributions. The equivalence approach actually contains many different types of measures, and this paper will pay special attention to the equivalent income, which is particularly attractive because of its simplicity and the possibility that it offers to measure individual situations in monetary units.

This paper scrutinizes the underpinnings of this approach, which was first elaborated by welfare economists seeking to perform interpersonal comparisons in terms of monetary measures while at the same time respecting individual preferences in virtue of the principle of "consumer sovereignty". Social choice theorists have been very critical about monetary 
measures of well-being, and many statisticians and social analysts were also skeptical about the welfare economists' attempt to put a money value on every component of wellbeing.

However, one finds a similar approach, somewhat generalized, in the theory of fair allocation. The connection between the theory of fair allocation and Rawlsian theories of social justice makes this approach look more interesting than could initially be thought in the context of traditional welfare economics.

Therefore, the thesis of this paper is that this approach may deserve a more positive assessment. Section 2 recalls the early developments of the notion of equivalent income in welfare economics and the objections it triggered. Section 3 examines the contribution of the theory of fair allocation and the philosophical underpinnings of the approach. Section 4 discusses the possibilities and difficulties of application of the equivalence approach. Section 5 concludes.

\section{Shady origins}

Economists have always been attracted by monetary measurement and income or wealth has a lot of intuitive appeal as a means of comparing individual situations in a market economy.

Two issues have complicated the matter. First, there are non marketed public goods that contribute to the standard of living without being recorded in ordinary income or wealth. Second, prices change all the time, and are different in different places, so that the nominal value of monetary measures is of little practical use for comparisons.

\subsection{Cost-benefit analysis and willingness-to-pay}

A key insight of cost-benefit analysis is that the two issues are one and the same, because market prices can be considered as environmental parameters of well-being just like the available public goods. Let $u_{i}\left(m_{i}, z_{i}\right)$ denote the utility ${ }^{1}$ (a representation of preferences) of individual $i$ endowed with nominal income or wealth $m_{i}$ and facing parameters $z_{i}$ (prices, public goods...). The variable $m_{i}$ is a real number, whereas $z_{i}$ is typically a vector with

\footnotetext{
${ }^{1}$ More precisely, this is usually called indirect utility.
} 
a certain finite number, $K$, of dimensions: $z_{i}=\left(z_{i k}\right)_{k=1, \cdots, K}$ We will assume throughout this paper that $u_{i}$ is increasing in $m_{i}$.

Consider a change of $\left(m_{i}, z_{i}\right)$ to $\left(m_{i}^{\prime}, z_{i}^{\prime}\right)$. The willingness-to-pay of $i$ for this change is the solution $w_{i}$ to the equation

$$
u_{i}\left(m_{i}^{\prime}-w_{i}, z_{i}^{\prime}\right)=u_{i}\left(m_{i}, z_{i}\right)
$$

One has $w_{i}>0$ when the change is "good", and $w_{i}<0$ when it is "bad". ${ }^{2}$ When $z_{i}^{\prime}=z_{i}$, one has $w_{i}=m_{i}^{\prime}-m_{i}$, as one should expect. For a small change $\left(d m_{i}, d z_{i}\right)$, from the equation

$$
u_{i}\left(m_{i}+d m_{i}-w_{i}, z_{i}+d z_{i}\right)=u_{i}\left(m_{i}, z_{i}\right)
$$

one computes

$$
w_{i}=d m_{i}+\sum_{k=1}^{K} \frac{\frac{\partial u_{i}}{\partial z_{i k}}}{\frac{\partial u_{i}}{\partial m_{i}}} d z_{i k} .
$$

Old-fashioned cost-benefit analysis, inspired by the compensation tests proposed by Kaldor, Hicks and Scitovsky, declares a change of the social situation from $\left(m_{i}, z_{i}\right)_{i \in N}$ to $\left(m_{i}^{\prime}, z_{i}^{\prime}\right)_{i \in N}$ (where $N$ denotes the population) to be good if $\sum_{i \in N} w_{i}>0 .{ }^{3}$ This has been the object of severe criticism from many authors, who objected that this method could lead to inconsistent (i.e., non-transitive) judgments and was generally biased in favor of the rich when willingness-to-pay increases with income. ${ }^{4}$ Modern cost-benefit analysis ${ }^{5}$ relies on a social welfare function $W\left(u_{i}\left(m_{i}, z_{i}\right)_{i \in N}\right)$, which guarantees transitivity of judgments and makes it possible to give priority to the poor. For a small change, one computes

$$
d W=\sum_{i \in N}\left(\frac{\partial W}{\partial u_{i}} \frac{\partial u_{i}}{\partial m_{i}}\right) w_{i}
$$

which shows that the sum of $w_{i}$ must be weighted by the social marginal value of money for $i, \frac{\partial W}{\partial u_{i}} \frac{\partial u_{i}}{\partial m_{i}}$.

\footnotetext{
${ }^{2}$ This is also called the compensating variation. The equivalent variation is the solution $e_{i}$ to

$$
u_{i}\left(m_{i}+e_{i}, z_{i}\right)=u_{i}\left(m_{i}^{\prime}, z_{i}^{\prime}\right)
$$

${ }^{3}$ Some prefer to use equivalent variations, or to check that both $\sum_{i \in N} w_{i}>0$ and $\sum_{i \in N} e_{i}>0$.

${ }^{4}$ See in particular Arrow (1951), Boadway and Bruce (1984), Blackorby and Donaldson (1990).

${ }^{5}$ See, e.g., Drèze and Stern (1987), Layard and Glaister (1994).
} 
This "modern" approach still suffers from a serious limitation. The social welfare function $W\left(u_{i}\left(m_{i}, z_{i}\right)_{i \in N}\right)$ is unspecified, and the basis on which interpersonal comparisons can be made, in order to compute the social marginal utility of money for different individuals, is left in the dark. Practitioners often resort to expedients, taking a decreasing function of income (e.g., the inverse) as the social marginal value of money. A related limitation is that this approach is not well suited for comparisons of social situations across populations with different preferences.

This difficulty with heterogeneous preferences also plagues the approaches which advocate using income or wealth as a proxy for well-being on the basis of a revealed preference argument. In absence of satiation, if a consumer buys a commodity bundle $x$ at prices $p$, we know that he prefers $x$ to all bundles $y$ such that $p y<p x$. But, obviously, this does not prevent another consumer with different preferences from preferring $y$ to $x$ in some instances.

\subsection{Money-metric utility and equivalent income}

The notion of equivalent income can be considered as a potential solution to these difficulties. It was initially proposed for the case when $z_{i}$ consists of the price vector in the market. Consider a situation in which all consumers face the same price vector $p_{0}$ and suppose that it is deemed reasonable to compare their situations in terms of income: the richer are the better-off. Suppose that the price vector changes from $p_{0}$ to $p$ for a small group of consumers. We can no longer compare them to the others directly in terms of nominal income. A simple solution consists in deflating nominal incomes by a price index, but ordinary indexes such as the Laspeyres, Paasche or Fisher indexes do not generally respect individual preferences. It is better to rely on hedonic price indexes which correctly reflect indirect preferences. Such a price index is a function $P_{i}\left(m_{i}, p\right)$ such that

$$
u_{i}\left(\frac{m_{i}}{P_{i}\left(m_{i}, p\right)}, p_{0}\right)=u_{i}\left(m_{i}, p\right) .
$$

Samuelson and Swamy (1974) and Samuelson (1974) observe that one can use $m_{i} / P_{i}\left(m_{i}, p\right)$ as a representation of individual $i$ 's preferences, a "money-metric utility". King (1983) proposes to call it the equivalent income, and we will use this expression when $z_{0}$ covers a broader class of parameters, reserving the expression "money-metric utility" for the case 
in which $z_{0}$ consists only in commodity prices.

The general definition of the equivalent income, when $z_{i}$ encompasses all relevant parameters, not just the market prices, ${ }^{6}$ is the following: $M_{i}\left(m_{i}, z_{i}\right)$ is the solution to

$$
u_{i}\left(M_{i}\left(m_{i}, z_{i}\right), z_{0}\right)=u_{i}\left(m_{i}, z_{i}\right)
$$

In this equation $z_{0}$ is a reference vector, which must be the same for all individuals to be compared. Comparing (1) to (2), one sees that

$$
M_{i}\left(m_{i}, z_{i}\right)=m_{i}-W_{i}\left(m_{i}, z_{i}, z_{0}\right),
$$

where $W_{i}\left(m_{i}, z_{i}, z_{0}\right)$ is $i$ 's willingness-to-pay to change from $z_{i}$ to $z_{0}$ when his income is $m_{i}$

Note that, even for continuous and monotonic preferences, (2) does not always have a solution. It may happen that for all $m, u_{i}\left(m, z_{0}\right)>u_{i}\left(m_{i}, z_{i}\right)$ or that for all $m, u_{i}\left(m, z_{0}\right)<$ $u_{i}\left(m_{i}, z_{i}\right)$. It is possible to exclude the first case by assuming that $u(0, z)$ takes the same value for all $z$, on the presumption that misery looks the same independently of prices and other parameters. Under this assumption, $u_{i}\left(0, z_{0}\right) \leq u_{i}\left(m_{i}, z_{i}\right)$ and the first case is eliminated. The second case is harder to eliminate, because one can imagine $z_{i}$ containing some benefits that are absent from $z_{0}$ and that "money can't buy". In such a case it might make sense simply to declare equivalent income to be infinite. In the rest of the paper we will ignore this possibility and assume that equivalent income is always well-defined with a finite value.

\subsection{Criticisms}

The equivalent income has attracted a lot of criticism, so much so that after a first wave of applications, ${ }^{7}$ its popularity quickly declined. We will simply explain the three main critiques here, and discuss them in more detail in the next section. The first critique is that the equivalent income does not incorporate sufficient information about subjective welfare, as it only depends on ordinal preferences. "A variation of one's intensities of

\footnotetext{
${ }^{6}$ The generalization of the notion of equivalent income to all environmental parameters was proposed by Hammond (1994).

${ }^{7}$ Deaton and Muellbauer (1980), King (1983), Muellbauer (1974a,b, 1975).
} 
pleasure or welfare cannot, therefore, find any reflection in this numbering system as long as the ordering remains unchanged." (Sen 1979, p. 11) In particular, if two individuals $i$ and $j$ have the same ordinal preferences and enjoy the same situation $(m, z)$, they will have the same equivalent income $M_{i}(m, z)=M_{j}(m, z)$ even though it may happen that $i$ is extatic whereas $j$ feels miserable.

An almost opposite criticism is that the equivalent income measure does not sufficiently reflect physical differences in individual situations (Kolm 2004). When two individuals have different preferences, their indifference curves can cross, so that the agent with a lower equivalent income may actually be better-off in all dimensions of the vector $(m, z)$. Indeed, assuming for simplicity that preferences are increasing in $(m, z)$, it is possible to have

$$
M_{i}\left(m_{i}, z_{i}\right)>M_{j}\left(m_{j}, z_{j}\right) \text { and }\left(m_{i}, z_{i}\right) \ll\left(m_{j}, z_{j}\right)
$$

because the first inequality simply requires

$$
W_{i}\left(m_{i}, z_{i}, z_{0}\right)<W_{j}\left(m_{j}, z_{j}, z_{0}\right)+m_{i}-m_{j}
$$

which may be possible when $i$ and $j$ have different preferences.

The third critique is that, in a simple setting in which individual direct utility simply depends on commodity consumption, a social welfare function $W$ whose arguments are equivalent incomes may fail to be quasi-concave in commodity consumptions, even when individual preferences are convex and $W$ is quasi-concave in equivalent incomes (Blackorby and Donaldson, 1988). This is incompatible with a minimal preference for equality. For instance, consider a two-agent population in which both individuals have the same direct utility function over two-commodity bundles $(x, y): U_{i}(x, y)=\min \{x, y+1\}$. Take reference prices $(1,1)$ and consider the allocation in which both individuals consume the bundle $(1,1)$. Their equivalent income is then equal to 1 . Now introduce some inequality, letting individual 1 consume $(1-\delta, 1)$ and individual 2 consume $(1+\delta, 1)$ for a small $\delta>0$. Then individual 1's money-metric utility is $1-\delta$ while individual 2's money-metric utility is $1+2 \delta$. For $\delta$ small enough, any differentiable and symmetrical social welfare function bearing on money-metric utilities will declare this change to be an improvement:

$$
d W=-\frac{\partial W}{\partial M_{1}} \delta+\frac{\partial W}{\partial M_{2}} 2 \delta>0
$$


if $\frac{\partial W}{\partial M_{1}}=\frac{\partial W}{\partial M_{2}}$, as should be the case for a symmetrical social welfare function because the two individuals are equally well-off in the initial situation.

The fourth criticism, developed by Roberts (1980) and Slesnick (1991), is that the equivalent income function depends on the reference vector $z_{0}$, and that if one wants to be able to perform interpersonal comparisons that are independent of the reference parameters severe restrictions are required (e.g., identical homothetic preferences in the context of reference parameters consisting of commodity prices). When individual preferences are different from one individual to another, with crossing indifference curves, the mere ranking of individuals simply cannot be independent of $z_{0}$, for the same reason that triggers the second critique described above.

In summary, the equivalent income has been criticized for being excessively and insufficiently materialistic, insufficiently egalitarian, and substantially arbitrary. Can it survive such deadly blows? To this list of criticisms one could add the devastating message of Arrow's impossibility theorem of social choice, which has discouraged many economists from seeking a reasonable criterion for the evaluation of individual and social situations. In particular, Arrow's theorem was especially targeted at the criteria which, like the equivalent income, are based only on individual ordinal non-comparable preferences. "This starkly negative finding became a major stumbling block to the empirical implementation of an explicit social welfare function. How is it possible to develop benevolent public policy if the only way to rank alternatives is to use the preferences of one person?" (Slesnick 1998, p. 2139).

\section{$3 \quad$ A second birth}

\subsection{The equivalence approach in fair allocation theory}

The theory of fair allocation ${ }^{8}$ makes a great use of a class of "egalitarian-equivalent" criteria, which bear a striking similarity with the equivalent income approach. But the equivalence approach in fair allocation is more general than the equivalent income. Consider a space $X$ with finitely many dimensions, and assume that individual situations are represented by vectors $x_{i}$ in this space. Assume moreover that individuals have continuous

\footnotetext{
${ }^{8}$ For a general survey of this theory, see Moulin and Thomson (1997).
} 
and monotonically increasing preferences in this space, letting the function $U_{i}: X \rightarrow \mathbb{R}$ represent individual $i$ 's preferences.

In the equivalence approach, individual indifference sets in $X$ are indexed with the help of a collection of nested sets $\left(B_{\lambda}\right)_{\lambda \in \mathbb{R}_{+}}$such that $\lambda \leq \lambda^{\prime}$ if and only if $B_{\lambda} \subseteq B_{\lambda^{\prime}}$. An individual's situation in a given allocation is evaluated by computing the "equivalent set" in the collection. This the set $B_{\lambda}$ that would give him the same satisfaction (if he could freely choose from $B_{\lambda}$ ) as the current allocation, i.e. the solution $B_{\lambda}$ to the following equation:

$$
U_{i}\left(x_{i}\right)=\max \left\{U_{i}(q) \mid q \in B_{\lambda}\right\} .
$$

Individual situations are then compared in terms of equivalent sets, which can be done unambiguously because these sets are nested: the larger, the better — assuming away satiation.

In the case when $X$ is $\mathbb{R}_{+}^{\ell}$ and represents the space of commodity bundles, the moneymetric utility computed at reference prices $p_{0}$ is an obvious example of this approach, with sets $B_{\lambda}$ which are simply budget sets for various income levels at the reference prices:

$$
B_{\lambda}=\left\{q \in X \mid p_{0} q \leq \lambda\right\}
$$

A more common example in the problem of dividing a fixed bundle of unproduced commodities is the indexation by the intersection of the indifference set and a reference ray containing a given bundle $\Omega_{0} \cdot{ }^{9}$ The corresponding sets $B_{\lambda}$ are defined as

$$
B_{\lambda}=\left\{q \in X \mid q \leq \lambda \Omega_{0}\right\}
$$

The equivalent income approach is therefore a particular example of the general equivalence approach. Let us now see how the objections against the equivalent income that were listed in the previous section can be assessed in this light.

\subsection{Arrow's theorem}

Let us start with Arrow's theorem. It is worthwhile recalling the setting and the conditions that form the components of the impossibility. The problem is to define an ordering (a

\footnotetext{
${ }^{9}$ This is how the egalitarian-equivalent concept was introduced in Pazner and Schmeidler (1978). Note that this method of representation of preferences was also quite popular in consumer theory (Malmquist 1953, Debreu 1959).
} 
complete and transitive binary relation) on a given set of alternatives, as a function of the individual preferences (orderings) on this set of alternatives. Three conditions are proved to be incompatible when there are at least alternatives, at least two individuals, and the domain of possible individual preferences is sufficiently rich: (1) Weak Pareto: An alternative unanimously preferred to another must be ranked above it; (2) Independence: The ranking of two alternatives must depend only on how these two alternatives (at the exclusion of the others) are ranked in individual preferences; (3) Non-Dictatorship: No individual must impose his strict preference on the social ordering for all possible profiles of individual preferences.

An important stream of social choice theory has proposed to retrieve possibility results by introducing additional information about individual situations, namely, interpersonally comparable utilities at the alternatives under consideration. ${ }^{10} \mathrm{~A}$ symmetrical social welfare function that is increasing in individual utilities generates an ordering that satisfies Weak Pareto and Non-Dictatorship. It also satisfies a weak form of Independence, because the way it ranks two alternatives depends only on the utility levels of the population at the two alternatives under consideration.

Other branches of welfare economics, however, have retained the ordinalist approach adopted by Arrow and obtained possibility results by ignoring or abandoning Independence. An example is given by cost-benefit analysis, because the computation of willingness-to-pay for a change in $z$ requires identifying a third alternative in which $m$ changes so as to restore the initial level of satisfaction. More interesting is the equivalent income approach, which characteristically violates Independence because in order to evaluate a particular social situation one has to compute the distribution of equivalent incomes, i.e., to construct another alternative. The theory of fair allocation has similarly obtained positive results by using more information about individual preferences than allowed by Independence. ${ }^{11}$ This is obviously the case with the equivalence approach, for

\footnotetext{
${ }^{10}$ For a synthesis on this approach, see Sen (1999).

${ }^{11}$ It has often been alleged that the theory of fair allocation obtains positive results because, contrary to social choice theory, it does not construct full rankings but only seeks to determine the subset of optimal allocations. This explanation cannot be accepted because the selection of a subset of allocations is, formally, equivalent to defining an ordering. The theory of fair allocation has actually also developed fine-grained rankings just like social choice theory. The correct explanation for its positive results is the violation of Independence by all solutions proposed in this theory. More on this issue can be found in
} 
the same reason as with the equivalent income approach. All these approaches consider it natural to take account of the indifference curves (or sets) of the individuals at the alternatives to be evaluated, and in this light the Independence axiom does not seem particularly compelling. As a consequence, Arrow's theorem should not be viewed as a serious obstacle, even in absence of interpersonally comparable utilities.

\subsection{Choice of references}

Let us now turn to the objection that the choice of reference parameters $z_{0}$ is crucial and arbitrary. For the equivalence approach more generally, what is at stake is the choice of reference sets $\left(B_{\lambda}\right)_{\lambda \in \mathbb{R}_{+}}$. The generality of the equivalence approach is helpful here because it suggests that the literature which criticizes the money-metric utility for being dependent on the reference price vector does not fully pursue the logic of its own critique. This literature accepts to take budget sets at given prices as the class of reference sets $\left(B_{\lambda}\right)_{\lambda \in \mathbb{R}_{+}}$. But this too should be questioned if one really wanted the analysis to be independent of the reference. Conversely, if one accepts to work with budget sets, why not examine if some reference prices are more plausible than others?

More directly, the answer to this objection is that if the equivalence approach depends on reference parameters, it can avoid arbitrariness if it develops an ethical theory of the choice of the reference. Some examples in the literature on fair social orderings show that rather natural axioms of fairness may force to adopt certain reference parameters. For instance, in a framework in which individual situations described by a contribution funded by a private endowment and a certain level of public good, Maniquet and Sprumont (2004) characterize a criterion which evaluates individual situations as follows: one computes the level of public good that, absent any contribution, would give the same satisfaction to the individual as the situation under consideration. Letting $\left(x_{i}, y\right)$ denote the vector of contribution $x_{i}$ and public good $y$, this method is an instance of the equivalence approach with sets $\left(B_{\lambda}\right)_{\lambda \in \mathbb{R}_{+}}$defined as (assuming monotonic preferences):

$$
B_{\lambda}=\left\{(x, y) \in \mathbb{R} \times \mathbb{R}_{+} \mid y \leq \lambda\right\}
$$

In their characterization, what drives the choice of such reference sets is a quite intuitive Fleurbaey et al. (2005). 
axiom saying that if $i$ and $j$ are such that $x_{i}<0<x_{j}$ (i.e., $i$ is subsidized while $j$ pays a contribution), it is an improvement to reduce $j$ 's contribution and $i$ 's subsidy by the same amount. Here is another example, found in Fleurbaey and Maniquet (2006). The setting there has consumption $c \geq 0$ and leisure $l \in[0,1]$, individuals being endowed with unequal productivities and heterogeneous preferences over consumption and leisure. The evaluation proposed in that paper relies on the reference sets

$$
B_{\lambda}=\left\{(c, l) \in \mathbb{R}_{+} \times[0,1] \mid c \leq \lambda l\right\}
$$

What drives this choice is an axiom saying that when all individuals have the same productivity, the laisser-faire allocation is a best allocation among all feasible allocations. These are just examples and the literature on fair social orderings is far from providing a complete theory of references for all settings. But the possibility of such a theory does not seem completely illusory.

\subsection{Egalitarianism}

The possibility for a social welfare function defined on money-metric utilities not to be quasi-concave in the quantities of commodities consumed actually finds an echo in a result from the fair allocation literature. ${ }^{12}$ Consider any social ordering which ranks two allocations on the sole basis of individual indifference curves at this allocation - this is a weak form of independence which is satisfied by the equivalence approach (including social criteria based on money-metric utilities) and other approaches as well. Assume in addition that it satisfies the following principle of transfer: if two individuals have identical preferences and one of them consumes more of every commodity than the other, then the allocation is improved if a transfer is made in order to reduce (but not eliminate) the inequality - this principle of transfer is satisfied by any quasi-concave social welfare function that is symmetrical for individuals with identical preferences. Assume finally that the social ordering satisfies Weak Pareto. Then this social ordering must give absolute priority to the worst-off when one considers two individuals with identical preferences but unequal consumptions. In practice social orderings satisfying this property are of the maximin or the leximin type. In their analysis, Blackorby and Donaldson (1988)

\footnotetext{
${ }^{12}$ See, e.g., Fleurbaey (2007b). A similar result is found in Maniquet and Sprumont (2004).
} 
considered a social welfare function that simply added up money-metric utilities. Their result is valid for any social welfare function with finite aversion to inequality between money-metric utilities. Granting absolute priority to the worst-off is indeed the only way to avoid the difficulty, and the result which has just been described confirms and extends this conclusion.

Is that a negative result? The literature on fair allocation tends to view it as a positive result because it forces a specific degree of inequality aversion and therefore reduces the range of acceptable social orderings, with a novel argument in favor the Rawlsian priority for the worst-off. Moreover it appears that the maximin is not so constraining because with various fairness principles it is possible to evaluate individual situations in many ways. For instance, even laisser-faire policies can be justified by maximin criteria if individual situations are measured in such a way as to sanctify the endowments of the individuals (intuitively, imagine that an individual's situation is measured by the gap between the value of his consumption and the value of his endowment).

An alternative reading of this result is that if one does not want to adopt the maximin or leximin criterion, one has to accept certain apparent violations of inequality aversion, but such violations may appear justifiable after all. Consider the equivalent income computed as the income that would be equivalent to an individual if his health were good (i.e., the reference is "good health"). Imagine two individuals with fair health. Suppose that their ordinary incomes in allocation $x$ are $(100,200)$ and their equivalent incomes $(80,150)$. Imagine that a regressive transfer between them would produce a new situation with ordinary incomes $(90,210)$ and equivalent incomes $(75,190)$. If one considers that, for two healthy individuals, the distribution $(75,190)$ is better than $(80,150)$, it is only logical, by Pareto-indifference, that for the less than healthy individuals under consideration, the regressive transfer yields an improvement. This is intuitively defensible if one observes that the regressive transfer triggers a reduction in both individuals' willingness to pay for a good health, especially for the beneficiary of the transfer. This example may also suggest that, in practice, such violations of the principle of transfer are unlikely to occur in dramatic proportions if the aggregator has enough inequality aversion. 


\subsection{Bundle dominance}

The idea that when an individual has a better situation in every dimension of life, he should be declared better-off is closely connected to a proposal made by Sen $(1985,1992)$ regarding the construction of an index of capabilities. His proposal consists in abandoning the project of a precise numerical index and in devising a partial ordering of individual situations based on the intersection of individual orderings. Assuming that individuals have well-defined preference orderings over capability sets or functionings, one can consider that individual $i$ is better off than individual $j$, in terms of capabilities or functionings, if this judgment is shared by all the preferences of the population (or all the preferences in a suitable domain). Rawls (1982) also invoked the possibility of this kind of unanimous judgment in order to identify the worst off group in terms of primary goods.

This "intersection" approach, however, has paradoxical consequences. ${ }^{13}$ Suppose that individual situations are represented by vectors in some space of capabilities or functionings, and that all reasonable preferences are monotonic. In this context, the intersection approach can motivate a dominance principle stipulating that an individual having more in all dimensions is better off. All monotonic individual preferences do indeed agree with this principle. But another natural way to respect individual preferences, especially if one wants to avoid paternalism, is to say that two situations that are deemed equivalent by an individual should be considered equivalent when they are given to this individual. Formally, consider a transitive but not necessarily complete ranking $\succeq$ of situations (individual vectors) $x \in X$, the expression $(x, i) \succeq(y, j)$ meaning that $i$ in situation $x$ is at least as well off as $j$ in situation $y$, and the expression $x R_{i} y$ meaning that $x$ is at least as good as $y$ for $i$ 's preferences (with $x I_{i} y$ denoting indifference). The dominance principle means that for all $i, j$, all $x, y \in X$, if $x \gg y$ then $(x, i) \succ(y, j)$. The nonpaternalism requirement means that for all $i$, all $x, y \in X$, if $x I_{i} y$ then $(x, i) \sim(y, i)$. Now, these two requirements are incompatible whenever there are individuals with different preferences (under mild assumptions). Because one can then find $x, y, z, w \in X$ and $i, j$ such that $x \gg y, z \gg w, x I_{i} w$ and $y I_{j} z$. By the dominance principle, $(x, i) \succ(y, j)$ and $(z, j) \succ(w, i)$, but by non-paternalism, $(x, i) \sim(w, i)$ and $(y, j) \sim(z, j)$, which violates transitivity.

\footnotetext{
${ }^{13}$ See Brun and Tungodden (2004).
} 
This fact implies that one must accept to relax one of the two requirements. It is natural to give priority to non-paternalism, because respecting individuals' preferences over their own situation should be more important than following their preferences over interpersonal comparisons. One can nonetheless seek to preserve as much of the dominance principle as is compatible with non-paternalism. A restricted dominance principle, for instance, stipulates that for some subset $A \subseteq X$, it holds that for all $i, j$, all $x, y \in A$, $x \gg y$ implies $(x, i) \succ(y, j)$. Under mild regularity conditions, the combination of this restricted dominance principle with non-paternalism implies that the ranking $\succeq$ must be of the egalitarian-equivalent sort. ${ }^{14}$ In particular, the subset $A$ over which dominance applies has to be a monotone path (an increasing curve in $X$ ) and interpersonal comparisons are performed as follows: $(x, i) \succeq(y, j)$ if and only if $a \geq b$, where $a, b \in A$ are defined by $x I_{i} a$ and $y I_{j} b$. The equivalent-income approach is an example of such a ranking, with a path defined by all levels of income associated with the reference values for the non-income dimensions $z_{0}$.

In conclusion, the violation of dominance should not be considered a specific problem of the equivalence approach because every non-paternalistic approach will share this feature. Moreover, the equivalence approach appears precisely as the best approach if one wants to satisfy as much of the dominance principle as is compatible with non-paternalism.

\subsection{Subjective welfare}

The criticism that money-metric utilities do not sufficiently take account of subjective welfare is sometimes formulated by reference to unequal needs that individuals may have. But needs can be incorporated in the $z_{0}$ vector, so that one can deal with this source of inequality easily (at least conceptually, if not practically) without leaving the framework of equivalent incomes.

More problematic is the issue of whether and how one should deal with purely subjective dimensions of well-being such as happiness or satisfaction. Here is one proposal, that is further developed in another paper. ${ }^{15}$ Happiness is catchword for a set of moods and affects that form a dimension of life, and individuals may have preferences about how

\footnotetext{
${ }^{14}$ See Fleurbaey (2007a).

${ }^{15}$ See Fleurbaey et al. (2008).
} 
much importance to give to such affects in their life as opposed to more objective dimensions of achievement. Another thing altogether is satisfaction as a judgment that each individuals casts on his life. The idea of non-paternalism and of dominance is precisely to respect such judgments when they take the form of preferences over the dimensions of life.

It is essential to note at this point that satisfaction welfarism, which compares individuals in terms of levels of satisfaction is less respectful of preferences than the equivalence approach. To see this, consider two individuals who have the same preferences over the dimensions of life and therefore always rank lives in the same way. They may both prefer the life of one of them to the other's, and the ranking of their lives with the equivalence approach will follow their own judgment. This configuration is however compatible with the better-off having a lower level of satisfaction. For instance, this is likely to happen if he was previously even better-off and is therefore disappointed to end up in his current situation, whereas the other is, on the contrary, on a growing path, and is therefore quite satisfied given his aspirations. Satisfaction welfarism would then go against the common judgment of these two individuals about who is the better-off. This criticism of welfarism is essentially an extension of Sen's $(1985,1992)$ famous criticism based on adaptive preferences: individuals who are objectively worse-off (for all reasonable preferences over life) may turn out to be just as satisfied because they adapt their aspirations to their circumstances. It is also related to Rawls' criticism of welfarism as developed in Rawls (1982). His argument is that comparing satisfaction levels between individuals amounts to using an overarching system of preferences over lives, whereas the only preferences over lives we can use are the heterogeneous and incommensurable preferences of individuals. This overarching system of preferences will typically contradict individual preferences because individuals do not compare each other in terms of satisfaction levels. The comparison is therefore not an empirical exercise based on the measure of some subjective quantity, it is an ethical exercise that has to involve fairness considerations.

In summary, according to the view briefly sketched here, one should deal with subjective well-being in two ways, distinguishing affects (happiness) from judgments (satisfaction with life). ${ }^{16}$ Affects form one dimension of life and can be incorporated in $z_{0}$ along other

\footnotetext{
${ }^{16}$ Surveys eliciting satisfaction with life with a quick question ("How are you satisfied these days...") typically do not thoroughly track judgments, because answers appear to be strongly influenced by current
} 
components - there is no reason to think that people only care about their mood and not at all about more objective achievements in their life. As far as satisfaction judgments are concerned, they actually appear to be better respected by the equivalence approach than by welfarism, as has just been explained.

As a conclusion to this section, one can observe that the criticisms raised against money-metric utilities and applicable more generally to the equivalence approach turn out to be less conclusive than it initially appears, and sometimes even turn to the advantage of the equivalence approach. Therefore, the convergence between the theory of fair allocation and an older branch of welfare economics appears rather promising.

\section{Toward applications}

The theory of fair allocation, however, has remained confined to specific models of economic allocation and is far from giving us a precise measure of well-being for a concrete comprehensive evaluation of individual situations. If we waited for this theory to deliver, we might wait for a very long time. Fortunately, it is not very difficult to imagine ways of applying the concept of equivalent income in concrete contexts.

Two difficulties have to be overcome. First, the selection of the relevant non-income dimensions to include in the computation and the definition of the reference vector $z_{0}$. Second, the collection of data on individual preferences. These two issues are briefly examined in turn in this section.

\subsection{Choosing references}

Let us explore how to incorporate a list of non-income dimensions in the computation of equivalent income. There is no claim of exhaustivity, and the general methodology by which the list should be made (e.g., with participatory groups in which the population can voice its priority concerns) will not be discussed here. As far as the choice of reference is concerned, a general principle may be helpful. Observe that when two individuals $i, j$ have $z_{i}=z_{j}=z_{0}$, their equivalent income equals their current income, so that comparing their situations can be made independently of their preferences. This property provides

mood. See, e.g., Diener (1994). 
a useful guide: a good reference vector $z_{0}$ should be such that we consider reasonable to compare individual situations having this vector simply in terms of income, without looking at individual preferences.

Another fact to be borne in mind when choosing a reference is that the greater the value of the reference, the lower in the ranking of equivalent incomes are the individuals who are especially keen on this dimension in their preferences. This is due to the fact that their willingness-to-pay to reach the greater level of reference is particularly high compared to other individuals. If the measurement of equivalent incomes is meant to serve for policy choice and if substantial priority is given to the worst-off, then a greater level of reference in a dimension will increase the degree of priority granted to the individuals who are disadvantaged in this dimension and suffer from it because they give a great importance to it. This is rather intuitive and provides additional indications for the choice of reference levels.

\subsection{Dimensions and references}

We now briefly examine how to choose the reference for a list of non-income parameters.

Prices. The case of market prices, which differ from one place or time to another, is easy to deal with in principle. One has to pick a reference price vector. A good reference vector should presumably be as close as possible to actual relative prices, for the following reason. If relative prices were the same everywhere and at all times, it would be natural to take these as the reference, whatever they are, because it would make sense to compare individuals directly in terms of income when they are identical in the non-income dimensions. By extension, for small variations the reference should be close to actual prices, and for large variations they should stand in a middle area.

One might, however, want to deviate from this line when market prices appear to unfairly favor some lifestyles over others, thereby distorting the opportunities of individuals. Suppose natural scarcity (or simply the market) is unfair to vegetarians because meat is a cheaper source of proteins than vegetables. Then we might want to take reference prices corresponding to an equal price for these two lifestyles. In this way, the committed vegetarians who suffer more than the occasional vegetarians and much more than the meat eaters would have a lower equivalent income even when their ordinary income is at 
the same level.

Leisure. For leisure there is some literature suggesting various solutions. ${ }^{17}$ The simplest, suggested in Maniquet (1998), consists in taking a reference quantity of leisure or of work. Another, which is closer to the money-metric utility, consists in taking a reference wage rate and focus on unearned income in the computation of equivalent income. Note the importance of taking the same reference wage rate for all individuals. One should not take the individual's own wage rate in order to compute a full income made of the addition of ordinary income with the value of leisure, because this would not respect people's preferences over consumption-leisure budget sets (i.e., one could have two individuals with identical preferences and different wage rates who prefer one budget set to another even though full incomes are ranked the opposite way).

The literature suggests that a good value for the reference wage rate should be rather low because a high reference wage rate implies that the individuals who are less averse to work are easily deemed to be badly-off. If anything, it is probably better to be biased in the opposite way, i.e., in the direction of considering the individuals who have a strong aversion to work to be the worst-off. Such aversion may be due to special needs, commitments on time, or difficulties of adaptation to work which are not easily observable directly.

One may also consider taking different references for people of working age and other people. For the latter, taking zero work as the reference is rather natural. Note that the literature on fair allocation suggests that zero work may actually serve as the reference for all individuals, even though the situation of "rentier" is no longer common for people of working age. ${ }^{18}$

Job quality. Taking account of the quantity of work does not eliminate the need to take account of other dimensions of work, which can be summarized as "job quality". Working conditions, social relations and degree of conflict, position in the hierarchy and degree of autonomy, recognition and status, opportunities for achievement and personal development, are among the main dimensions. The choice of a reference in this domain

\footnotetext{
${ }^{17}$ For a survey, see Fleurbaey (2005).

${ }^{18}$ This was already suggested in Kolm (1968). A related possibility is to take zero as the reference wage rate. This is equivalent to taking zero work as the reference quantity of work when preferences are monotonic in leisure, but not equivalent if preferences are not monotonic (even with a fixed income that does not depend on their work, individuals may want to work).
} 
is not independent of the choice made with respect to leisure. If zero work is taken as the reference, for instance, job quality is automatically taken into account because someone with a lower job quality (everything else equal) will accept a lower equivalent income in the form of unearned income. In this case there is no need to choose a reference job quality. If the unskilled wage rate is taken as the reference, it is natural to take the average unskilled job quality as the reference.

Health and longevity. As far as health is concerned, a good health is the obvious reference to have, and this is the common practice. Indeed, when it is assumed that the population under consideration is healthy (as in Rawls' theory of justice, or simply in the literature on income inequality), no author suggests that we should compare individual situations not only in terms of income but also depending on how much they enjoy being healthy. This means that healthy individuals can be compared independently of their preferences, or equivalently, that the correct reference is good health (and therefore maximum longevity). ${ }^{19}$

Security. There is an element of risk in health, but let us address risk (for income, health, personal property) globally. A very natural reference in this case, which is largely used in the insurance literature, is the certainty situation. Computing the certaintyequivalent income, when dealing with income risk, is a quite standard exercise.

Family size. The use of equivalent income is widespread for the comparison of households of different demographic compositions. The literature has traditionally adopted the unitary model of household utility and imagined that there is a utility function comparing vectors of household income and household size. A serious challenge for this literature has been the impossibility to retrieve sufficient information about comparisons across different sizes from observed behavior (demand data). A more promising approach - also more in line with the theory developed here - consists in considering individual preferences over consumption bundles involving private consumption and local public goods consumed in the household. ${ }^{20}$ The natural reference in this case is the single. The single-equivalent income is the income one would need to obtain an equally satisfactory consumption bundle if one had to live alone. ${ }^{21}$

\footnotetext{
${ }^{19}$ An axiomatic defense of this reference can be found in Fleurbaey (2005).

${ }^{20}$ This approach is developed in Browning et al. (2006).

${ }^{21}$ Fleurbaey and Gaulier (2007) show that if households always spend half of their budget on private
} 
This approach focuses on consumption bundles and neglects the social benefits (or costs) from family life. The issue of social connections is discussed below.

Public goods. There are public goods outside the household. The excludable public goods, however, seem amenable to the same treatment as ordinary commodities for the purpose of computation of equivalent incomes. For instance, those who live far from an opera have a price for an opera evening which includes transport and hotel. If the reference price vector includes a lower price, this will reduce their equivalent income, especially if they like opera. This kind of computation is exactly identical to what is done for any ordinary commodity. As far as pure public goods are concerned, the literature on fair allocation ${ }^{22}$ is not very helpful, because it considers a partial equilibrium model in which only contributions to the public good are considered, which amounts to assuming that individual private endowments are fair. Presumably, the natural approach is to pick a reference vector of public goods, but it is not easy to see what a "normal" vector is exactly, although the range of reasonable values is probably not very hard to identify.

Social connections and status. There is no difficulty in principle to incorporate social relations and social status in the computation, because individuals typically have well-defined preferences over these dimensions as well. But here again, the reference is not easy to define. Presumably some middle level, rather than an extremely low or extremely high level, would be appropriate.

\subsection{Individual preferences}

The second question to be examined is how to collect data on individual preferences. This issue is not independent of the kind of preferences that one would like to know. The immediate preferences that people express when asked directly in a contingent-valuation questionnaire are not the same as the preferences they reveal in their choices, and none of them are identical to the deeper preferences that people would express if they were given sufficient information and sufficient time for reflection and analysis of the issues. Presumably, the deeper preferences are the relevant ones.

goods (and the rest on local public goods), and if individuals are identical within each household (but not necessarily across households), then the OECD equivalence scale based on the square root of the household size coincides with the singe-equivalent income.

${ }^{22}$ See Maniquet and Sprumont $(2004,2006)$. 
There are three potential sources of data on preferences. The first is revealed preferences through choices made by individuals. This method is limited to dimensions for which a choice is actually possible. Moreover, it is not very reliable if one is interested in individuals' deep preferences, because choice is often affected by irrationality and contingent factors that perturb the individuals at the moment of choice. The second potential source is contingent-valuation questionnaires (stated preferences). This method is limited by the impossibility to give individuals sufficient time to reflect on the questions and sufficient incentives to think seriously about the issue. The third source is happiness and satisfaction surveys, which do not directly ask for preferences but which can serve to retrieve preferences on the basis of the link between individuals' situation and their stated satisfaction or happiness. The limitation of this method is that happiness and satisfaction surveys capture the mood of the day more than a serious evaluation of life in all its dimensions. Even more problematic is the strong influence of individuals' variable adaptation to their situation, which introduces a noise that is hard to correct unless one takes care of recording the evolution of individuals' situation in the past and the situation of their group of reference. ${ }^{23}$

All in all, none of the three methods is satisfactory and reliable. But one can hope that progress is to come from a greater sophistication of each method and from their association in the same surveys. For lack of data at the individual level, Becker et al. (2005) and Fleurbaey and Gaulier (2007) compute equivalent incomes at the level of countries, with rough estimates of average willingness-to-pay. The collection of individual data, however, seems necessary in order to obtain a reasonable description of the distribution of equivalent incomes.

\section{Conclusion}

The reference to willingness-to-pay and the computation of equivalent incomes does not mean that everything is marketable or that "a dollar is a dollar", and it does not push us back into the pitfalls of the old cost-benefit analysis. It simply amounts to comparing individuals in a simple hypothetical world in which they are all equal over the non-

\footnotetext{
${ }^{23}$ See, e.g., Clark and Oswald (2002), Kahneman and Krueger (2006).
} 
income dimensions and differ only in the income dimension. This hypothetical world is constructed so that all individuals are indifferent between their current situation and their "equivalent" situation in the hypothetical world, and so that it makes sense to compare them in terms of income because, when they all enjoy the reference levels for non-income dimensions, their preferences over these dimensions do no longer seem relevant for such comparisons. This approach is compatible with giving priority to the worst-off and its main motivation is respecting individuals' preferences over the dimensions of life.

The main criticisms which have been raised against the money-metric utility are not decisive and the emergence of the equivalence approach in the theory of fair allocation justifies renewed interest in the notion of equivalent income. It appears as particularly recommended if one seeks a method of measurement of well-being that respects individual preferences. Serious challenges remain in the perspective of empirical applications, such as the choice of reference levels for the various dimensions, a topic for which the theory is still quite incomplete, and the collection of reliable data on individual preferences.

\section{References}

Arrow K.J. 1951, Social Choice and Individual Values, New York: Wiley.

Becker G., T. Philipson, R. Soares 2005, "The quantity and quality of life and the evolution of world inequality", American Economic Review 95: 277-291.

Blackorby C., D. Donaldson 1988, "Money metric utility: A harmless normalization?" Journal of Economic Theory 46: 120-129.

Blackorby C., D. Donaldson 1990, "A review article: The case against the use of the sum of compensating variations in cost-benefit analysis", Canadian Journal of Economics 23: 471-494.

Boadway R., N. Bruce 1984, Welfare Economics, Oxford: Basil Blackwell.

Browning M., P.A. Chiappori, A. Lewbel 2006, "Estimating consumption economies of scale, adult equivalence scales, and household bargaining power", Boston College Working Paper \#588.

Brun B., B. Tungodden 2004, "Non-welfaristic theories of justice: is the "intersection approach" a solution to the indexing impasse?", Social Choice and Welfare, 22: 49-60. 
Clark A.E., A.J. Oswald 2002, "A simple statistical method for measuring how life events affect happiness", International Journal of Epidemiology 31: 1139-1144.

Deaton A.S., J. Muellbauer 1980, Economics and consumer behaviour, Cambridge: Cambridge University Press.

Debreu G. 1959, "Topological methods in cardinal utility theory", in K. J. Arrow, S. Karlin and P. Suppes (eds.) Mathematical methods in the social sciences, Stanford University Press.

Diener E. 1994, "Assessing subjective well-being: Progress and opportunities", Social Indicators Research 31: 103-157.

Drèze J., N. Stern 1987, "The theory of cost-benefit analysis" in A.J. Auerbach, M. Feldstein (eds.), Handbook of Public Economics, Amsterdam: North-Holland.

Fleurbaey M. 2005, "Health, wealth and fairness", Journal of Public Economic Theory 7: 253-284.

Fleurbaey M. 2006, "Social welfare, priority to the worst-off and the dimensions of individual well-being", in F. Farina, E. Savaglio (eds.), Inequality and Economic Integration, London: Routledge.

Fleurbaey M. 2007a, "Social choice and the indexing dilemma", Social Choice and Welfare 29: $633-648$.

Fleurbaey M. 2007b, "Two criteria for social decisions", Journal of Economic Theory 134: 421-447.

Fleurbaey M., G. Gaulier 2007, "International comparisons of living standards by equivalent incomes", CEPII 2007-03.

Fleurbaey M., K. Decancq, E. Schokkaert 2008, "What good is happiness?", mimeo.

Fleurbaey M., K. Suzumura, K. Tadenuma 2005, "The informational basis of the theory of fair allocation", Social Choice and Welfare 24: 311-342.

Fleurbaey M., F. Maniquet 2006, "Fair income tax," Review of Economic Studies 73: $55-83$.

Kahneman D., A. Krueger 2006, "Developments in the measurement of subjective wellbeing", Journal of Economic Perspectives 20: 3-24.

Kolm S.C. 1968, "The optimal production of social justice", in H. Guitton, J. Margolis éds, Economie Publique, Paris: Ed. du CNRS. 
Hammond P.J. 1994, "Money metric measures of individual and social welfare allowing for environmental externalities", in W. Eichhorn ed., Models and Measurement of Welfare and Inequality, Berlin: Springer.

Maniquet F. 1998, "An equal-right solution to the compensation-responsibility dilemma", Mathematical Social Sciences 35: 185-202.

Maniquet F., Y. Sprumont 2004, "Fair production and allocation of an excludable nonrival good", Econometrica 72: 627-640.

Maniquet F., Y. Sprumont 2005, "Welfare egalitarianism in non-rival environments", Journal of Economic Theory 120: 155-174.

Muellbauer J. 1974a, "Inequality measures, prices and household composition", Review of Economic Studies 41: 493-504.

Muellbauer J. 1974b, "Household composition, Engel curves and welfare comparisons between households", European Economic Review 5: 103-122.

Muellbauer J. 1975, "Aggregation, income distribution and consumer demand", Review of Economic Studies 42: 525-543.

King M. 1983, "Welfare analysis of tax reforms using household data", Journal of Public Economics 21: 183-214.

Kolm S. C. 2004, Macrojustice. The Political Economy of Fairness, New York: Cambridge University Press.

Layard R., S. Glaister (eds.) 1994, Cost-Benefit Analysis, Cambridge: Cambridge University Press.

Malmquist S. 1953, "Index numbers and indifference surfaces", Trabajos de Estadistica 4: 209-242.

Moulin H., W. Thomson 1997, "Axiomatic analysis of resource allocation problems", in K.J. Arrow, A.K. Sen, K. Suzumura (eds.) 1997, Social Choice Re-examined, vol. 1, International Economic Association, New York: St Martin's Press and London: Macmillan. Pazner E., D. Schmeidler 1978, "Egalitarian equivalent allocations: A new concept of economic equity", Quarterly Journal of Economics 92: 671-687.

Rawls J. 1982, "Social unity and primary goods," in A.K. Sen, B. Williams éds, Utilitarianism and Beyond, Cambridge: Cambridge University Press.

Roberts K.W.S. 1980, "Price independent welfare prescriptions", Journal of Public Eco- 
nomics 13: 277-298.

Samuelson P.A. 1974, "Complementarity: An essay on the 40th anniversary of the HicksAllen Revolution in Demand Theory", Journal of Economic Literature 12: 1255-1289.

Samuelson P.A., S. Swamy 1974, "Invariant economic index numbers and canonical duality: Survey and synthesis", American Economic Review 64: 566-593.

Sen A.K. 1979, "The welfare basis of real income comparisons: A survey", Journal of Economic Literature 17: 1-45.

Sen A. 1985, Commodities and Capabilities, North-Holland, Amsterdam.

Sen A. 1992, Inequality re-examined, Oxford: Clarendon Press.

Sen A.K. 1999, "The possibility of social choice," American Economic Review 89: 349-378.

Slesnick D.T. 1991, "Aggregate deadweight loss and money metric social welfare", International Economic Review 32: 123-146.

Slesnick D.T. 1998, "Empirical approaches to the measurement of welfare", Journal of Economic Literature 36: 2108-2165. 